\title{
From the Editor....
}

January 2006, a memorable year, a memorable month, when you look back no less than hundred years, when our Engineers got together to form an association which evolved to be the Institution of Engineers Sri Lanka. A matter definitely worth commemorating and celebrating for, as this hundred years of modern Engineering marks a renaissance in a nation and a civilization of outstanding Engineering achievements.

With such colourful history and achievements, one could easily sit on ones laurels in blissful complacency of being the greatest. While in a sense this is true, we should take advantage of the lead achieved by our profession to face the challenges of the future, which will definitely require more Engineering than any thing else.

In this second century of our association we must rise to take the reins in guiding our still 'Developing Country' to eventual 'Development'. To do so research in "Engineering for Sri Lanka, with resources of Sri Lanka" should be our theme. Through the journal 'ENGINEER', we at the Institution of Engineers provide our members, a widely publicized forum, for discussion, critical evaluation and dissemination of research findings in Engineering. So, I wish the existence of such, be a motivation for our members to conduct Engineering research for the country.

Eng. Dr. T. M. Pallewatta

Editor 